\title{
Excedencia voluntaria, negativa injustificada al reingreso y derecho a la prestación por desempleo.
}

\author{
Carmen Viqueira Pérez \\ Catedrática de Derecho del Trabajo y de la Seguridad Social. Universidad de Alicante
}

Resumen: El despido que encierra la negativa injustificada de la empresa al reingreso tras una excedencia voluntaria coloca al trabajador en situación legal de desempleo, pero la prestación no podrá reconocerse si, al tiempo del despido, éste no se encuentra en alta en la seguridad social. Sobre la obligación de la empresa de cursar el alta y sobre los efectos del incumplimiento de esta obligación gira la sentencia comentada.

Palabras clave: Excedencia. Desempleo. Alta. Reingreso. Despido.

Abstract: The dismissal that contains the unjustified refusal of the company to re-enter after an unpaid leave places the worker in a legal situation of unemployment, but the benefit may not be recognized if, at the time of dismissal, he was not registered with social security. The commented sentence considers the obligation of the company to register the worker and the effects of default.

Keywords: Unpaid leave, re-enter, unemployment, registration, dismissal.

\section{Introducción}

La escasa regulación que el ET dedica a la excedencia voluntaria es inversamente proporcional al cúmulo de problemas interpretativos que genera y en torno a los que se ha ido articulando un cuerpo de jurisprudencia imprescindible para perfilar una institución en la que la posición del trabajador no cuenta con excesivas garantías. El contexto de fragilidad que proporciona la excedencia voluntaria se advierte especialmente cuando el trabajador ha de ejercitar derecho al reingreso preferente que ostenta y se encuentra con la injustificada negativa de la empresa, no sólo porque ante la negativa de la empresa se abre paso un panorama de actuación nada sencillo (acción por despido o acción declarativa de derechos), sino porque, además, el acceso a la protección por desempleo puede resultar igualmente complejo.

En efecto, buen ejemplo de ello es el litigio que la sentencia analiza y resuelve, en el que el SPEE se niega a reconocer el derecho a percibir la prestación por desempleo por entender que la trabajadora, si bien se encuentra en situación legal de desempleo, no cumple el requisito de encontrarse en alta o situación asimilada, porque la empresa no procedió a cursar el alta el día que negó el derecho a la readmisión. La sentencia, avalando una posición garantista, concluye que la empresa debió readmitir a la trabajadora y -consecuentemente- cursar su alta, y el hecho de que esta obligación se haya incumplido no puede arrostrar efectos adversos en el derecho a la protección por desempleo que tiene la trabajadora injustamente despedida. 


\section{Identificación de la resolución judicial comentada}

Tipo de resolución judicial: sentencia.

Órgano judicial: Tribunal Supremo. Sala Cuarta.

Número de resolución judicial y fecha: sentencia núm. 781/2021, de 13 de julio.

Tipo y número recurso: RCUD núm. 4111/2018.

ECLI: ES:TS:2021:2924.

Fuente: CENDOJ.

Ponente: Excmo. Sr. D. Ángel Blasco Pellicer.

Votos Particulares: carece.

\section{Problema suscitado. Hechos y antecedentes}

El litigio que la sentencia analiza y resuelve gira en torno a la negativa del SPEE a reconocer el derecho a percibir la prestación por desempleo por entender que la trabajadora, si bien se encuentra en situación legal de desempleo, no cumple el requisito de encontrarse en alta o situación asimilada.

Tras disfrutar de una excedencia voluntaria de un año en las dos empresas en las que venía prestando trabajo como limpiadora (ISS Facility Services -con una jornada del $38,5 \%$ y ECOGLYMP con una jornada de 25,6\%), al solicitar el reingreso, la trabajadora se encuentra con la negativa de una de ellas, a la que demanda por despido. La empresa reconoce -en conciliación judicial- la improcedencia del despido y abona la correspondiente indemnización a la trabajadora que, con amparo en la existencia del despido, solicita la correspondiente prestación por desempleo que es denegada por el SPEE por no encontrarse en situación de alta o asimilada.

En instancia, la trabajadora ve desestimada su pretensión que, sin embargo, es acogida en suplicación (STSJ Madrid Rec.230/2018) en base a la idea de que la excedente despedida se encuentra en situación legal de desempleo y el hecho de que la empresa no la readmitiera y no cursara de alta no puede perjudicar el derecho de la trabajadora a percibir la prestación por desempleo. Este es el debate que llega a casación y aborda la sentencia comentada.

\section{Posición de las partes}

Aunque es notable la parquedad de la sentencia (tanto la de suplicación como la de casación) a la hora de dar cuenta de las posiciones de las partes, de lo señalado en una y otra cabe extraer que el SPEE (recurrente en casación) deniega la prestación por desempleo porque la trabajadora, al tiempo del despido, no está en alta ni en ninguna de las situaciones asimiladas al alta. De algunos pasajes incluso parece inferirse que, en su negativa, el SPEE también cuestiona "la mayor", esto es, cuestiona que la trabajadora se encuentre en situación legal de desempleo.

Por su parte, la trabajadora aduce su derecho a obtener la prestación por desempleo porque el reconocimiento del despido en conciliación la coloca en situación legal de desempleo y porque debe entenderse también cumplido el requisito del alta ya que, al finalizar la excedencia, la empresa debió readmitirla y cursar el alta en la seguridad social, y el hecho de que optara por incumplir una y otra obligación no puede perjudicar su derecho a obtener la protección por desempleo.

\section{Normativa aplicable al caso}

Es normativa aplicable al caso la que ordena el derecho de reingreso que ostenta el excedente voluntario (a); la que establece los requisitos de acceso a la protección por desempleo (b); y la que establece los efectos que sobre las prestaciones ha de tener el incumplimiento de las obligaciones de afiliación, alta y cotización (c). 
A) Por lo que hace al derecho de reingreso que ostenta el trabajador tras la excedencia, la normativa aplicable al caso viene constituida por el art. 46, en sus apartados 2 y 5 .

Art. 46.2 ET: 2. "El trabajador con al menos una antigüedad en la empresa de un año tiene derecho a que se le reconozca la posibilidad de situarse en excedencia voluntaria por un plazo no menor a cuatro meses y no mayor a cinco años. Este derecho solo podrá ser ejercitado otra vez por el mismo trabajador si han transcurrido cuatro años desde el final de la anterior excedencia voluntaria".

Art. 46.5 ET: "El trabajador en excedencia voluntaria conserva solo un derecho preferente al reingreso en las vacantes de igual o similar categoría a la suya que hubiera o se produjeran en la empresa".

B) Por lo que hace a los requisitos de acceso de la prestación por desempleo, interesa tener en cuenta los art. 266 LGSS (que enumera los requisitos de acceso a la prestación) art. 166 LGSS (que se ocupa de establecer las situaciones asimiladas al alta) y el art. 2 RD 625/1985 (que establece las situaciones asimiladas al alta a efectos de la prestación por desempleo).

Art. 266 LGSS: "Para tener derecho a las prestaciones por desempleo las personas comprendidas en el artículo 264 deberán reunir los requisitos siguientes: a) Estar afiliadas a la Seguridad Social y en situación de alta o asimilada al alta en los casos que legal o reglamentariamente se determinen".

Art. 166 LGSS: "Situaciones asimiladas a la de alta.

1. A los efectos indicados en el artículo 165.1, la situación legal de desempleo total durante la que el trabajador perciba prestación por dicha contingencia será asimilada a la de alta.

2. También tendrá la consideración de situación asimilada a la de alta, con cotización, salvo en lo que respecta a los subsidios por riesgo durante el embarazo y por riesgo durante la lactancia natural, la situación del trabajador durante el período correspondiente a vacaciones anuales retribuidas que no hayan sido disfrutadas por el mismo con anterioridad a la finalización del contrato.

3. Los casos de excedencia forzosa, traslado por la empresa fuera del territorio nacional, convenio especial con la Administración de la Seguridad Social y los demás que señale el Ministerio de Empleo y Seguridad Social, podrán ser asimilados a la situación de alta para determinadas contingencias, con el alcance y condiciones que reglamentariamente se establezcan.

4. Los trabajadores comprendidos en el campo de aplicación de este Régimen General se considerarán, de pleno derecho, en situación de alta a efectos de accidentes de trabajo, enfermedades profesionales y desempleo, aunque su empresario hubiera incumplido sus obligaciones. Igual norma se aplicará a los exclusivos efectos de la asistencia sanitaria por enfermedad común, maternidad y accidente no laboral.

5. El Gobierno, a propuesta del titular del Ministerio de Empleo y Seguridad Social y previa la determinación de los recursos financieros precisos, podrá extender la presunción de alta a que se refiere el apartado anterior a alguna o algunas de las restantes contingencias reguladas en el presente título.

6. Lo establecido en los dos apartados anteriores se entenderá sin perjuicio de la obligación de los empresarios de solicitar el alta de sus trabajadores en el Régimen General, conforme a lo dispuesto en el artículo 139, y de la responsabilidad empresarial que resulte procedente de acuerdo con lo previsto en el artículo siguiente.

7. Durante las situaciones de huelga y cierre patronal el trabajador permanecerá en situación de alta especial en la Seguridad Social". 
Art. 2 RD 625/1985. "1. Se considerarán situaciones asimiladas al alta, a efectos de la prestación por desempleo, las siguientes:

a) La excedencia forzosa por elección para un cargo público o sindical.

b) El cumplimiento del servicio militar o la prestación social sustitutoria.

c) El traslado o desplazamiento temporal por la Empresa fuera del territorio nacional.

d) El retorno de los trabajadores emigrantes.

e) La situación de invalidez provisional.

f) La liberación por cumplimiento de condena o libertad condicional.

2. Asimismo se considerará situación asimilada al alta la de los trabajadores fijos discontinuos que no sean llamados al reiniciarse la actividad correspondiente".

C) Por lo que hace a los efectos que sobre las prestaciones ha de tener el incumplimiento de las obligaciones de afiliación, alta y cotización, resulta aplicable el art. 281 LGSS que establece la automaticidad del derecho a las prestaciones.

Art. 281 LGSS: "La entidad gestora competente pagará las prestaciones por desempleo en los supuestos de incumplimiento de las obligaciones de afiliación, alta y de cotización, sin perjuicio de las acciones que pueda adoptar contra la empresa infractora y la responsabilidad que corresponda a esta por las prestaciones abonadas".

\section{Parte dispositiva}

La sentencia comentada -STS 2924/2021 (Rec. 4111/2018)- desestima el recurso de casación para unificación de doctrina interpuesto por el SPEE frente a la sentencia de la Sala de lo Social del Tribunal Superior de Justicia de Madrid de 11 de julio de 2018 (Rec.230/2018) cuyo pronunciamiento confirma, avalando así la conclusión de que, dado que la empresa debió readmitir a la trabajadora y -consecuentementecursar su alta, el hecho de que esta obligación se haya incumplido no puede arrostrar efectos adversos en el derecho a la protección por desempleo que tiene la trabajadora injustamente despedida.

Así, la sentencia afirma que, dado que la empresa reconoció la improcedencia del despido que encierra la no readmisión de la trabajadora excedente "hay que entender que en tal fecha la empresa tenía la obligación de haber dado de alta en Seguridad Social a la trabajadora, que no puede verse perjudicada por la falta de cumplimiento de dicha obligación por parte del empresario, por lo que hay que entender cumplido el requisito exigido por el artículo 266 a) LGSS según el que quien solicite la prestación de desempleo debe estar en alta o situación asimilada al alta ya que la demandante despedida tenía derecho a estar en alta en el RGSS al sobrevenir situación legal de desempleo protegida".

\section{Pasajes decisivos}

El hilo argumental de la sentencia descansa en dos ideas. Por un lado, tiene como punto de partida una afirmación ya sustentada por el Tribunal Supremo de modo constante: que la situación en que se encuentra el trabajador excedente cuando la empresa reconoce en conciliación que su negativa al reingreso constituye un despido injustificado es análoga a la situación en la que se encuentra un trabajador injustamente despedido a partir de la fecha del despido. Efecto inmediato de esta equiparación es que, de cara a la protección por desempleo, en uno y otro caso el trabajador se encuentra en situación legal de desempleo "por despido". Por otro lado, sostiene la sentencia que el reconocimiento de la improcedencia del despido implica el reconocimiento del incumplimiento de la obligación de reingreso (esto es, el incumplimiento de la obligación de readmitir al trabajador dar de alta al trabajador) y 
que ese incumplimiento empresarial no puede perjudicar el derecho de la trabajadora a acceder a la protección por desempleo.

En efecto, de modo contundente y con apoyo en doctrina constante del Tribunal (STS 19 diciembre de 2011, Rec. 218/2011; 11 de junio de 2012, Rec. 3860/2011 y de 14 de marzo de 2019, Rec. 2785/2017) en la sentencia se mantiene que "la situación del trabajador excedente voluntario que, cuando una vez concluido el periodo de excedencia voluntaria pactado pretende la reincorporación a la empresa y ésta no le readmite procediendo a conciliar su despido como improcedente, es análoga a la del trabajador injustamente despedido a partir de la fecha del despido". De ello, lógicamente, cabe inferir que la situación del excedente despedido injustamente con respecto al acceso a la protección por desempleo es idéntica a la del trabajador despedido injustamente por otra causa y, por ello, se encuentra en situación legal por desempleo: "la empresa reconoció la improcedencia del despido surgido a raíz de la no readmisión de la trabajadora excedente y que ello constituye situación legal de desempleo (Artículo 267.1.a) $3^{\circ}$ LGSS)".

A renglón seguido y con igual contundencia, la sentencia mantiene que la trabajadora "despedida tenía derecho a estar en alta en el RGSS al sobrevenir la situación legal de desempleo protegida" porque, al reconocer la empresa que la no readmisión constituyó un despido, reconoce que debió proceder a la reincorporación y debió cursar el alta ("hay que entender que en tal fecha la empresa tenía la obligación de haber dado de alta en Seguridad Social a la trabajadora").

Sentado lo anterior, la sentencia concluye que el incumplimiento de esta obligación no puede perjudicar el derecho de la trabajadora a percibir la prestación por desempleo "por lo que hay que entender cumplido el requisito exigido por el artículo 266 a) LGSS según el que quien solicite la prestación de desempleo debe estar en alta o situación asimilada al alta".

Aunque la sentencia no lo señale expresamente, lógica consecuencia de ello es que la Entidad Gestora abonará a la trabajadora la prestación por desempleo sin perjuicio de las acciones que puedan asistirle frente a la empresa incumplidora.

\section{Comentario}

Es casi un lugar común decir que la excedencia voluntaria se caracteriza por la debilidad del derecho de reingreso que, a la finalización de la excedencia, ostenta el trabajador. A esta debilidad que, de partida, caracteriza el derecho se añaden, además, un amplio y variado elenco de cuestiones dudosas en torno a la interpretación de su exacto alcance y contenido que aportan un nada desdeñable grado de incertidumbre que en nada favorece a la posición del trabajador. Sentado esto, no hace falta agotar los argumentos para comprender que, en este contexto de fragilidad, la protección del trabajador frente a la situación de desempleo derivada de la negativa de la empresa al reingreso adquiere especial relevancia.

La protección por desempleo del trabajador al que la empresa niega injustificadamente la readmisión tras una excedencia voluntaria, puede plantear dos puntos de fricción: la configuración de la situación legal de desempleo (a) y el cumplimiento del requisito del alta (b). Sobre los dos aporta la sentencia comentada una visión lúcida y claramente orientada a la protección del trabajador.

a) La negativa injustificada de la empresa al reingreso encierra un despido $y$, consecuentemente, el excedente no readmitido se encuentra en situación legal de desempleo por despido. Ello es así, a mi juicio, aún cuando no se haya producido la impugnación del acto extintivo y el trabajador cuente únicamente con una acreditación de su solicitud de reingreso y de la injustificada negativa empresarial, porque la decisión empresarial que impide la reincorporación viene a poner fin a la relación laboral, aunque opere en un contexto de ausencia de prestación de trabajo. Y cuando, como sucede en el caso que analiza la sentencia, la trabajadora ha hecho frente al desconocimiento de su derecho impugnando el despido y la empresa ha reconocido en conciliación judicial la improcedencia del acto extintivo, no cabe duda alguna de 
que ello es así; no cabe duda de que la trabajadora se encuentra en situación legal de desempleo derivada del despido.

La sentencia incide en este punto, recordando la doctrina sentada en Sala General por la STS de 19 diciembre de 2011 (Rec. 218/2011) donde se mantiene que "la situación del trabajador excedente voluntario que, cuando una vez concluido el periodo de excedencia voluntaria pactado pretende la reincorporación a la empresa y ésta no le readmite procediendo a conciliar su despido como improcedente, es análoga a la del trabajador injustamente despedido a partir de la fecha del despido". De ello, lógicamente, cabe inferir que la situación del excedente despedido injustamente con respecto al acceso a la protección por desempleo es idéntica a la del trabajador despedido injustamente por otra causa y, por ello, se encuentra en situación legal por desempleo, como se afirma claramente en la sentencia comentada "la empresa reconoció la improcedencia del despido surgido a raíz de la no readmisión de la trabajadora excedente y que ello constituye situación legal de desempleo (Artículo 267.1.a) $3^{\circ}$ LGSS)".

b) Para el acceso a la prestación además de los requisitos de control específico (situación legal de desempleo, inscripción como demandante de empleo y suscripción del compromiso de actividad) es preciso cumplir los requisitos contributivos clásicos: afiliación, alta y cotización. En el supuesto que resuelve la sentencia, la empresa se limitó a exhibir su negativa ante la petición de reingreso de la trabajadora, a la que no dio de alta en la seguridad social y esta falta de alta es la que determina que el SPEE deniegue el reconocimiento del derecho a la prestación por desempleo.

Ciertamente, podría pensarse que la empresa, cuando se niega reincorporar al trabajador, no tiene obligación de cursar el alta ya que, al fin y a la postre, la decisión empresarial opera en un contexto de ausencia de prestación de trabajo y dar de alta al trabajador implicaría colocarle en una posición "más ventajosa que la propia de la excedencia voluntaria en que se encontraba" (STSJ Madrid 14 marzo 2018 Rec.1619/2017-). Pero esa perspectiva -a mi juicio- no es correcta porque, ante la solicitud de la trabajadora, la obligación de la empresa es readmitirla y -obviamentecumplir con las obligaciones que a la readmisión se anudan, como es significadamente- la de cursar la correspondiente alta en la seguridad social. La negativa injustificada de la empresa no sólo opera en el terreno de la excedencia poniéndole fin- sino también en el de la relación contractual, impidiendo al trabajador la prestación de trabajo y poniendo fin a la relación contractual. La sentencia es contundente en este sentido cuando afirma que la trabajadora despedida "tenía derecho a estar de alta en el RGSS" cuando sobreviene la situación de desempleo protegido, porque en la fecha en que se produce la no readmisión "la empresa tenía la obligación de haber dado de alta en la seguridad social a la trabajadora”.

La cuestión se desplaza así a otro terreno. La duda no gira ya en torno a los efectos que la falta de alta deba tener con respecto a la prestación por desempleo que pretende lucrar la trabajadora, sino en torno a los efectos que deban anudarse al incumplimiento de la obligación que tiene la empresa de dar de alta a la trabajadora. Con acierto y contundencia, la sentencia afirma que la trabajadora "no puede verse perjudicada por la falta de cumplimiento de dicha obligación por parte del empresario" y esa es, sin duda, la base de la que debe partirse: la trabajadora no puede verse perjudicada y, en consecuencia, ha de entenderse cumplido el requisito de alta y expedita la vía para obtener el reconocimiento del derecho a percibir la prestación por desempleo.

Aunque la sentencia no entra en ello (sí lo menciona la sentencia recurrida), sentada la obligación de la empresa de cursar el alta de la trabajadora (como deber ínsito en su obligación de readmitir), el incumplimiento abre la vía de la automaticidad del derecho a las prestaciones (art. 281 LGSS) de modo que el SPEE abonará la prestación correspondiente "sin perjuicio de las acciones que pueda adoptar contra la empresa infractora y la responsabilidad que corresponda a esta por las prestaciones abonadas". 


\section{Apunte final}

La escasa regulación de que es objeto la excedencia voluntaria (o, más exactamente, la finalización de la excedencia voluntaria) ha venido generando un cúmulo de cuestiones dudosas que -a falta de mejora legislativa- han encontrado respuesta en la jurisprudencia. La sentencia comentada es ejemplo claro de la importancia que esta labor tiene por cuanto que, en el contexto de fragilidad que se despliega en torno a la negativa injustificada de la empresa a la readmisión del trabajador, en ella se apunta una solución claramente garantista que facilita el acceso a la protección por desempleo del excedente injustamente no readmitido. 